Thank you for publishing with Taylor \& Francis. A PDF proof of your article is attached for urgent proofreading along with an 'Agreement for the Transfer of Copyright'. Please read the following instructions carefully.

\title{
RETURNING YOUR PROOFS/CORRECTIONS
}

(1) Please print out the article, check it carefully, and attend to any queries listed on the proof query sheet at the end of the article. Amendments should be marked clearly on to the hard copy in ink (do not mark the PDF file).

(2) Please send corrections back by fax or urgent post to the address below within 72 hours of receipt. When faxing, marks must be clear and legible in all instances and not too close to the margin in case they are omitted during transmission. Alternatively, you may send your corrections by email (quoting Journal Title, page and line number of each correction), to the email address proof-queries@tandf.co.uk, ensuring all corrections are clear and concise. (Please keep a copy of all the corrections as a backup). Please find attached a copy of some commonly used proofreading marks.

\section{AGREEMFNT FOR THE TRANSFER OF COPYRIGHT}

Please print out, complete and sign the attached 'Agreement for the Transfer of Copyright' form. This should be returned to the address below. (If you have already signed and returned a copyright form by prior arrangement, then please disregard this request. However, you should be aware that non-receipt of a completed form could possibly delay publication of your article).

\author{
Address for return of the proofs/signed copyright form: \\ 'Journal Title (not Article Title)' \\ Floor 2, Journals Production \\ Taylor \& Francis Ltd \\ 4 Park Square \\ Milton Park, Abingdon \\ Oxfordshire OX14 4RN, UK
}

Tel: $\quad+44 \quad(0) 1235828600$

Fax: $+44 \quad(0) 1235829000$

Email: proof-queries@tandf.co.uk

\section{E-PRINTS (Electronic Offprints) / OFFPRTNTS}

An E-print (PDF file, from which you may print or distribute no more than 50 copies to friends or colleagues) may be sent to you, via email, up to two weeks prior to publication, and a copy of the issue in which the article appears will be sent by standard mail. Alternatively, you may receive 50 printed offprints (if you wish to take this option, you should advise us by email). If you wish to order additional offprints or copies of the journal issue, then please contact the Production Editor named on the ' $\mathrm{CC}$ ' list on this email.

Many thanks in advance for your co-operation. If you have any queries, please contact us at: proof-queriesdtandf.co.uk

http://www.tandf.co.uk

http://www.taylorandfrancis.com

If you have problems accessing the PDF file, please access the Adobe website and download the free Acrobat Reader from:

Http://www. adobe.com/products/acrobat/readstep.html 


\section{PROOF CORRECTION MARKS}

\section{Instruction}

Leave unchanged

Extraneous marks or damaged letter

Delete

Insert or replace text

Add $(\Lambda)$ or substitute $(/)$ : full stop

decimal point
comma
semi-colon
colon
apostrophe or
$\quad$ quotation mark
superscript
subscript
hyphen
short or long rule
oblique

Wrong typeface or size

Change to: roman (upright)

italic

capital letters

small capitals

bold type

lower case letters

Greek letters

Delete and close up

Reduce space

Close up space

Insert space

Make space in line equal

Insert space between lines

Reduce space between lines

New paragraph

Run on, no new paragraph

Transpose letters or words

Transpose lines

Take character to next line

Take character to previous line

Raise text on page

Lower text on page

Check vertical alignment

Check horizontal alignment

\section{Mark in margin}

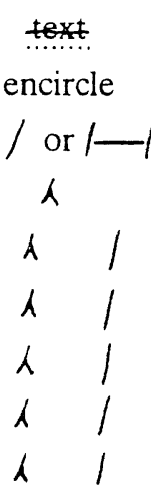

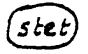

$x$

o

/ text to be added

$\odot$

○्ञ

'/

i)

(9)

$\begin{array}{ll}1 & 1 \\ 1 & 1 \\ 1 & 1 \\ 1 & 1 \\ 1 & 1 \\ 1 & 1\end{array}$

encircle

encircle

underline

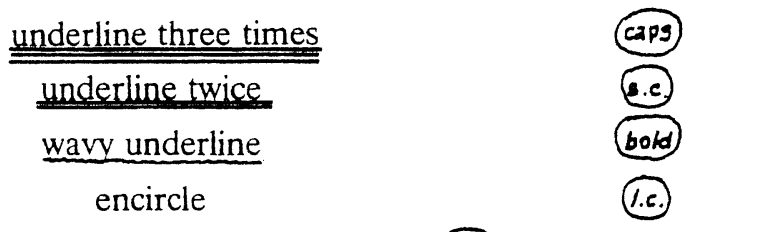

encircle

coळpy

in / copy

in cópy

infopy

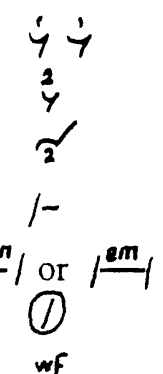

(rom

(e.c.

(1..).

(g) adding Greek letter

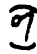

less \#

$\approx$

\#

eq*
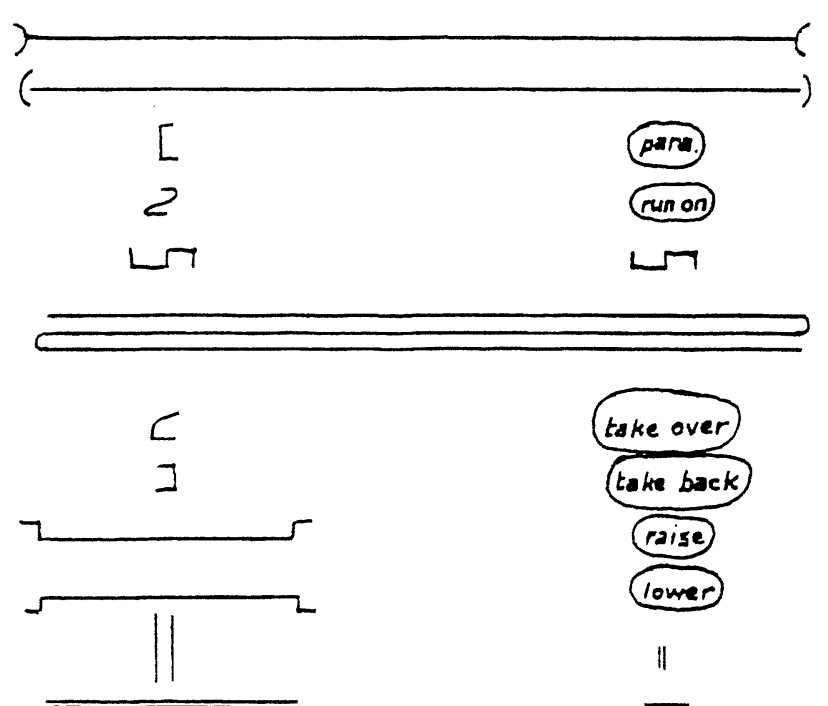


\title{
Children's participation in school grounds developments: creating a place for education that promotes children's social inclusion
}

\author{
GREG MANNION \\ (Originally received 27 October 2000; accepted in final form 21 August 2002)
}

\begin{abstract}
This paper advances the idea that 'education for the social inclusion of children' is similar but different to 'inclusive education' as it has come to be understood and used by some authors and UK government documents. 'Inclusive education' tends to carry an inward emphasis on the participation of children in the education system (with discussions on school culture, transitions, truancy, exclusion rates, underachievement, and school leaving age). In contrast, education for the promotion of children's social inclusion requires an outward emphasis on children's participation in 'mainstream' society while they are still children. The latter emphasis is seen to be lacking in educational policy discourse in Scotland though a recent shift in policy towards education for active citizenship is noted. Examples are provided to show how many policy statements enact a limitation on the scope for education to promote children's social inclusion by emphasizing children's deficits as social actors and focussing on the 'condition' of social exclusion. The paper draws on an empirical study of children's participation in changing school grounds in Scotland. The analysis shows how the enclosure of learning in books, classrooms and normative curricula was challenged. Learning from school grounds developments was constructed relationally and spatially, but the scope of what was to be learned was often delineated by adults. The paper closes with a discussion of how education that promotes the social inclusion of children will benefit from seeing both children and adults as current though partial citizens and using socio-spatial opportunities for the generation of uncertain curricula through their shared and/or differentiated participation.
\end{abstract}

\section{Children's social exclusion/inclusion}

Social exclusion has been used by the UK government as a shorthand term for a 'condition' brought about when people or areas suffer from a combination of linked problems such as unemployment, poor skills, low incomes, poor housing, high crime, bad health and family breakdown (Social Exclusion Unit 2001: 10). Because the UK is seen to have comparably high levels of social exclusion, tackling social exclusion, reintegrating the 'excluded', promoting social inclusion and providing services in a more 'joined up' manner have become critical aims for the current Labour Government. These aims have been supported by a range of policies on specified issues such as school exclusion and truancy, sleeping rough, teenage pregnancy, children and young people 'at risk', and deprived neighbourhoods. In themselves, these strategies may not be entirely inappropriate given poverty levels, but the consequence is a sustained

Greg Mannion is at the Institute of Education (Room A44), University of Stirling, Stirling FK9 4LA, UK; e-mail: g.b.g.mannion@stir.ac.uk

International fournal of Inclusive Education ISSN 1360-3116 print/ISSN 1464-5173 online C 2003 Taylor \& Francis Ltd http://www.tandf.co.uk/journals

DOI: $10.1080 / 1360311032000063173$

TIED Vol. 7 No. 1 Paper IED 100181 Page Proofs 7/3/03 Genesis 
emphasis on the 'condition of the socially excluded', the redemption of 'at risk' children and youth, and the vulnerability of those in poverty.

While social exclusion is sometimes referred to as a condition, it is also described as a 'process' that has happened in space and time (Aries 1973, Cunningham 1995) that results in children's detachment from the many organizations and communities that comprise society, and from the rights and obligations of mainstream society (Hayton 1999: 35). In medieval times, there was acceptance that children from the age of 7 were virtually integrated into the 'adult world' without any transitional phase (Mannion 1999, Appendix H). Children did much the same work and wore the same clothes. Child-specific toys and clothing were unheard of. Games and songs were shared by children and adults. In 'traditional' societies adults and children engaged in communal sporting activities and work outdoors. In modern times, deWinter (1997) argues that while most children may have been rescued from the problems associated with child labour, lack of hygiene and other social dangers, in achieving this we have placed them in a special glasshouse of 'Youthland'. A Scottish study confirms this view finding that only about one in five organizations had developed good practice guidelines for consulting and involving children and young people (Dorrian et al. 1999: 32). We 'raise' children by keeping them 'down' by striving to get them off the street (and into safe playgrounds or play centres), trying to keep them safely away from the perceived dangers of the adult world and into various form of 'care', precluding them from work of various kinds and placing them into the educational enclosures we call schools (Lankshear et al. 1996). This following poem was spotted on a display in a Scottish primary school. Its authorship and context of writing are unknown, but it provides an indication of the sorts of civic engagement children themselves see as 'adult' though we need not necessarily infer that these are all things from which children are completely excluded or would wish to be included in:

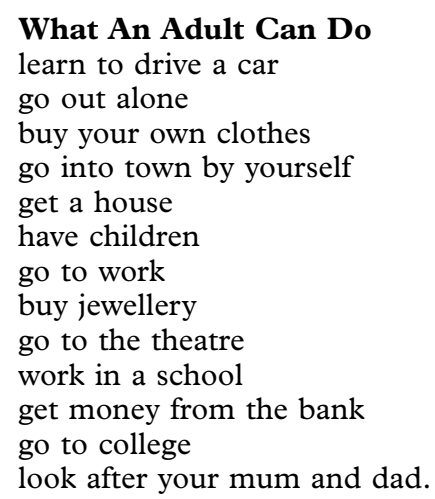

Children's rights enshrined in the UN Convention on the Rights of the Child (UNICEF 1995) offer another way of understanding children's social exclusion and inclusion. Children's rights are promoted along three strands: participation, protection and provision. As will be demonstrated by the policy examples below, the focus on exclusion, poverty and risk leads to concern for children's protection to the detriment of children's participation 
(Matthews et al. 1999, Roberts 2001: 53). Yet, there may be reasons why the children's rights imperative is interpreted in this way in education circles. Freeman (2000) argues that the 1989 Convention by defining the role of education as preparing the child for 'responsible life in a free society ...' (Article 29(d)) fails to address the current citizenship rights of pupils at school. The emphasis on education as 'preparation' serves to defer and limit the debate on children's current social inclusion.

The Scottish educational landscape has much in common with other parts of the UK and the developed world by being set against a backdrop of economic and cultural processes of globalization (Edwards and Usher 2000, Education, Culture and Sport Committee 2002). Commentators claim that the drive for market competitiveness and workforce development means that education responds with a concern for knowledge and skill acquisition while active citizenship moves to the back burner (Field 2000). However, the advent of the Scottish Parliament has encouraged a fresh spotlight on the importance of democratic renewal. Education for citizenship is emerging as a key way of mobilizing an active citizenry.

\section{Education and children's social inclusion}

The report Preventing Social Exclusion (Social Exclusion Unit 2001) mentions education in three main contexts: truancy, early school leaving and underachievement. By inverse logic, we might expect that social inclusion can be achieved through education if people attend school, do well and stay on, but this argument supports a narrowly focussed view of how education might address young people's social exclusion and civic engagement. As examples will demonstrate, the narrow focus is brought about by:

- deferring young people's social inclusion because of the focus on the condition of 'adult' social inclusion;

- limiting the scope for children's current social inclusion by focusing the debate inward on attendance and school-based achievement;

- limiting the scope for future inclusion by seeing their future inclusion as assured by being employed; and

- being concerned with joining up professionally delivered services to 'at risk' children and young people which emphasizes young people's deficits and positions them as the recipients of services.

\section{Deferral and limitation}

The focus on the adult condition of social exclusion leads government educational strategy towards a deferral of the process of promoting children's social inclusion or civic participation while they are still children:

By improving educational attainment, by making the education system more inclusive, and by integrating support for children and families around the school system, the prospects of all children can be improved. But some children face special difficulties which, if not addressed, could all too easily consign them to exclusion in later life. (Scottish Office 1999) 
Inclusive education has become synonymous with providing additional pupil support, smoothing pupil transitions between education, training and employment sectors, being concerned with skills, and employability, continuity and progression (Beattie Committee 1999). Other authors discuss educational inclusion/exclusion to special education provisions and see a need to change school culture in order to provide for a grater diversity of learner types (Carrington 1999, Corbett 1999). Inclusive education emphasizes an inwardly directed participation in the education system. In contrast, education for the promotion of children's social inclusion in society requires outwardly directed participation of children in society. 'Educational inclusivity' is taken to mean the involvement in schooling without any critical appraisal of what schooling achieves. 'Mainstream society' is constructed as being outside the school walls into which children and young people may later gain access if they 'participate' properly now as pupils. This form of policy discourse deploys an impoverished model of children's participation and inclusion in society supporting deWinter's (1997) view of education as a Youthlandish enclosure offering limited identification opportunities for children. Children are located as pupils-in-need-ofpreparation in a manner that may not be entirely in their interest as a social group. Through this discourse, children are at risk of future social exclusion so we need not address their current experience as citizens. Because employment is seen as the remedy for social exclusion (Byrne 1999), it is also the taken-for-granted purpose of education. However, things may be about to change. A recent discussion paper on the purposes of education in Scotland mentions that the ideas of children's rights and parents' rights are seen to pose a new challenge to the purposes of schooling (Education, Culture and Sport Committee 2002).

\section{Children in deficit}

The consistent emphasis apparent in Scottish policies relating to children's services, of which education services are now subsumed, is that professionals must work more closely together to deliver what is needed for children and families, especially those who are most 'vulnerable'. Like other government-led, interventionist, multi-agency initiatives, education services are also required to reflect client needs but, in seeking to do so, problems are often firmly located by the discourse 'in' children and families.

\footnotetext{
New Community Schools are fundamental to the Government's twin strategies to raise educational attainment and promote social inclusion. The climate is right for the development of this new integrated and inclusive approach to involve families more directly in children's learning. . . . Integration of services is essential, and the school is an excellent site for this to become a reality. This will require radically new approaches. Such integrated approaches will enable action to be taken early to meet the needs of vulnerable children through swift identification of problems and immediate referral to support services. (Scottish Office 1998: 1)
}

Initiatives such as New Community Schools, Sure Start, and Early Intervention programmes also seek to minimize risk of children's future social exclusion. The version of social inclusion promoted allows for the 
engagement of communities and families in children's learning which, in itself, is not a 'bad thing'. Children's informal learning outside school is also seen to be important but primarily as a support for formal education inside. What is noticeable is that 'education' and 'inclusion' always get associated in an inward direction in the formal educational system and not outwardly towards society or communities. The result is a preoccupation with overcoming the barriers to the attendance, attainment and achievement of all children and young people in mainstream schooling and the aim of promoting of social inclusion through schooling is easily avoided. Similarly, in New Community Schools, 'pupil engagement' does not carry meanings of full civic engagement in society. It has come to mean 'engagement in school, particularly for disaffected groups of young people' (Sammons et al. 2002: 8 ) in line with the stated aims of the government with respect to the social inclusion of school age children: 'to provide children with the best possible start in life, to identify difficulties at an early stage and address them effectively, to raise levels of school attendance and educational attainment, and to support families' (Scottish Office 1999: 6.26). Government ministers now accept that there is a good case in principle for the establishment of a Commissioner for Children and Young People, yet, even in this context, the deferral of their participation until they are adults and the emphasis on children's deficits rather than agency is maintained. 'Children from disadvantaged backgrounds suffer a range of lasting problems: poor educational performance, more contact with police and a wider range of health problems - all of which will impact on their adult lives' (Scottish Executive 2002: 2). Joined-up policy initiatives validate new ways of working interprofessionally, but they do not in themselves guarantee the devolution of power from policy-makers and professional practitioners to community leaders, parents or children (Nixon et al. 2000: 330). Integrated policy initiatives run the risk of overemphasizing children's incompetent 'becomings' and simply positioning children as recipients-of-services and 'in need' of professional help. As Popkewitz (2001: 200) notes, within the discourse of the child as learner is:

also an inscription of an unspoken opposition - the child who is in need, who is to be rescued through education - the child who is categorised as the school leaver, disadvantaged, at-risk, or from non-functioning 'homes'. These characteristics and distinctions are of the child who is to be saved or rescued for society and . . to be disciplined in the present so as to ensure a future that is to be civilised.

\section{Education for/as citizenship}

As we have seen, the attention has been on keeping children attached to school without any serious questioning of what form of social inclusion of children is achieved through educational provision while children are still children. Taking a more process-oriented definition of children's social inclusion (Hayton 1999) would lead us to see the importance of children's engagement in, and education about, the many organizations and communities that comprise society. It would focus on the process of actively gaining of rights and obligations of mainstream society. This calls into question not only whether 
children are merely in attendance at school or attaining, but also what other contact with the adult world is encouraged and what civic institutions children are made accessible and through schooling. Education as citizenship, rather than about it, would challenge the school effectiveness paradigm of educational change requiring it to take on board a complimentary paradigm of children's social inclusion or children's effectiveness while pupils.

There is on-going interest in the work of pupil councils and new legislation now requires that schools take on board children's views in school planning. However, time and again, authors point out how children's views in schools councils often do not get beyond tokenistic participation and tend to deal with only certain issues like uniform, toilets and school dinners (e.g. Holden and Clough 1998: 56). It has been common for teachers to see education for citizenship as 'the process of assisting children to become active citizens' (Holden and Clough 1998: 13). The construction of children as inactive or 'just practising' agents in need of help has similarly tended to epitomise the debate. Typically, the teacher is the one who will be central in assisting children and the teacher is the 'knowledgeable other' (Holden and Clough 1998: 17). Latterly, however, Scotland is experiencing a rise in interest in a different view of education for citizenship. Scotland now has its first national parliament in almost 300 years and a desire to learn how to nurture and sustain its own distinctive form of democracy. Rising scepticism about traditional structures of representative democracy and low voter participation in elections add fuel to the debate on how education might now address the need for a more active citizenry. The result is a noticeable shift in the policy talk away from the limited and deferred model of children's inclusion in society towards a more expanded view of what is possible. The recent consultation paper on education for citizenship defines citizenship as being about enjoying rights and exercising responsibilities in the various types of community to which people belong. Crucially, this is new 'talk' advocated that 'Young people should be regarded as citizens of today rather than citizens in waiting' (Learning and Teaching Scotland 2000: Section 1.1) in a discussion document while in the rest of the UK the dominant discourse is on the development of skills agenda albeit through participation in 'real experiences' of active citizenship outside school (Qualifications and Curriculum Authority 2000). Both documents shifted the inclusion agenda for schools from an inward direction (getting young people and families involved in mainstream schooling) to an outward direction (seeing learning in less bounded and more community-focussed ways). The consultation document and the recent response from government on citizenship education advocates a spatially enlarged forum for education for citizenship that includes but goes beyond formal lessons in classrooms about discrete subject areas. The documents encourage planned learning experiences within a more inclusive and participative school culture and ethos. The new discourse continues to construct young people as currently active citizens in interaction with each other, with adults and with the community:

Approaches to all aspects of education for citizenship in the classroom, or the wider life of the school or community should be informed by the awareness that citizenship is best learnt through experience and interaction with others. In short, learning about 
citizenship is best achieved by being an active citizen. (Learning and Teaching Scotland 2002: 10)

\section{Spaces for participation}

Until recently, ideas found in much UK government policy talk about children's social inclusion through educational experience have been shown to be limited and insufficient. Next, an analysis of data from research on school grounds developments in Scotland between 1996 and 1999 shows that some educational experiences appeared to promote degrees of children's social inclusion. The analysis of levels of participation and aspects of children's learning and engagement shows how the enclosure of learning in books, classrooms and normative curricula was brought into question and the challenge of promoting children's social inclusion via educational practice is thrown into relief.

\section{Methodology}

The research, documented below, took a two-phased case study approach in that it was holistic, contextually well defined and field-oriented (Stake 1995: 48). The first phase involved intensive fieldwork in a playground in one primary school. The choice of case was dependent not on its typicality but on its potential for being instrumental (Stake 1995: 88) in providing insight into the issue of children's participation and the spatial aspects of spatial participation and learning in a school grounds setting. The second phase of the project involved at least one visit to each of 22 other schools. The distinctive criterion for selection was the school's reputation among practitioners (designers, activists, educators and a range of other informants from organizations and schools) for having involved children in decisionmaking and in making physical changes to grounds. Nineteen of the selected schools were primaries, two were secondary schools and one was an urban nursery school. Twelve of the primaries were small and in rural settings. There was one larger rural school. The respondents (boys and girls aged between 7 and 13) came from schools in seven different local authority regions of Scotland. Gaining access involved communication with teachers and parents and dealing with the many ethical aspects of working closely with children. In most schools, I worked closely with a team of children selected for their high levels of 'insider knowledge' about various grounds developments. These teams took me on 'guided walks' of grounds while providing a commentary on the changes. One key part of the data involved conducting a survey of children's views of their involvement in projects using participatory research tools (O'Kane 2000). Hart's (1992) ladder of participation (figure 1), an adaptation of Arnstein's (1979) earlier model, provided a framework for encouraging children to think about and evaluate their position in the culture of decision-making in a school grounds project and an easy way of recording their experience. A version of this ladder with supplementary 'child-accessible' language was presented and discussed in 


\section{Hart's Reconfiguration of Arnstein's Ladder of Participation}

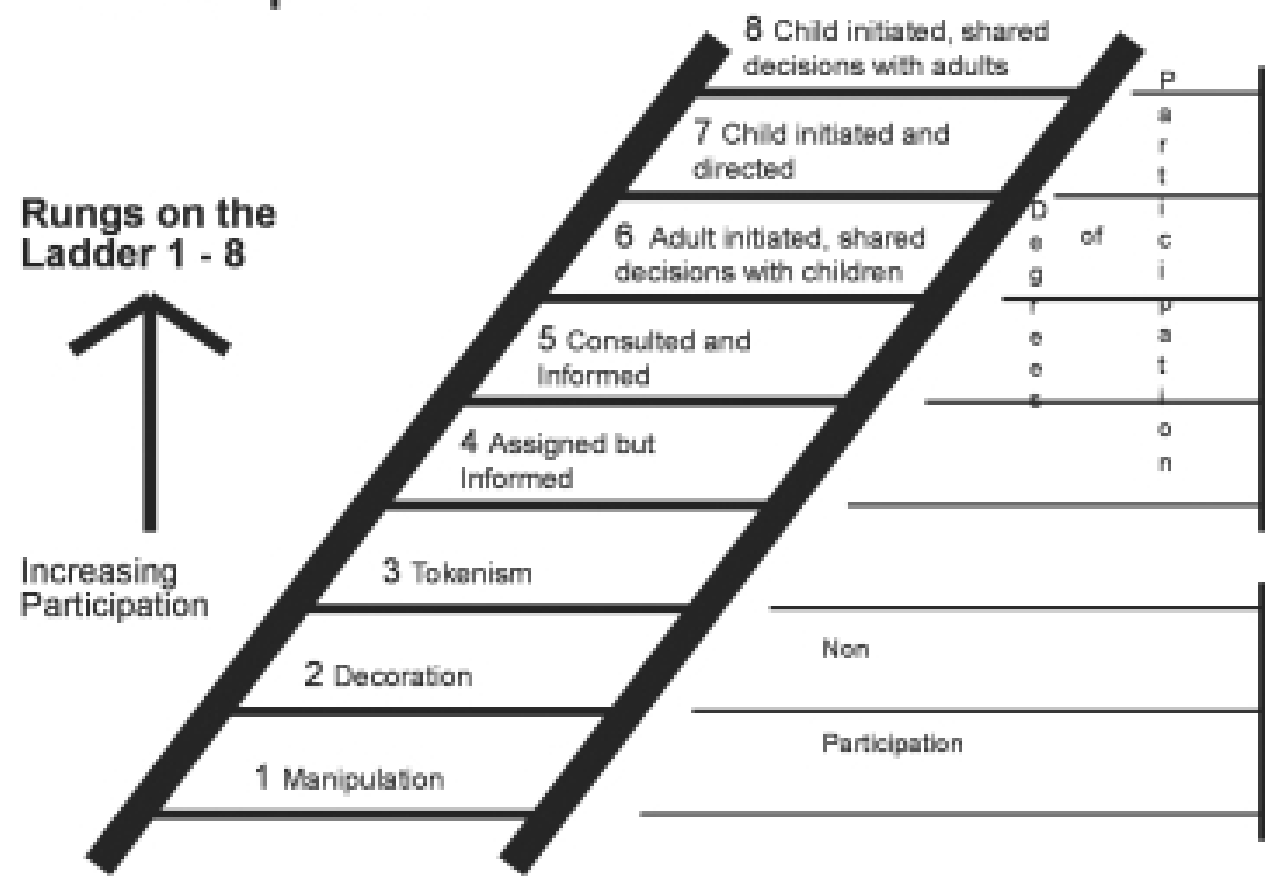

Hart (1992); Arnstein (1979)

Figure 1. Hart's reconfiguration of Arnstein's ladder of participation.

classrooms. After discussion, children were invited to record one number (from 1 to 8 ) that 'best represented the participation of those involved'. Children were advised that it was not a test and that there was no 'right' answer and that higher numbers 'up the ladder' were not necessarily 'better'. Children were asked to record their views in private on separate pieces of paper and to write any additional comments. These were collected and responses were not divulged to their carers, teachers or others unless there was a unanimous agreement to do so and only then if there was a strong sense that the projects were viewed favourably by children and adults. Children were given the option of not taking part if they so wished. Teachers were often present but were supportive of the need for confidentiality and the accurate recording of children's views whatever they may have been.

\section{Findings}

Respondents in the smaller rural schools selected levels 6, 7 and 8 more commonly than in any other subgroup of schools (figure 2). These levels were denoted on the ladder as: 8 , Child-initiated, shared decisions with adults; 7 , child-initiated and directed; and 6, adult-initiated, shared decisions with 
children. As such, the data from the rural schools subgroup represented the highest recorded levels of agency and shared action with adults.

Most noticeable was the high occurrence of level 6 (and the low occurrence of choices at level 8). It was apparent that adult-initiated projects with a large degree of shared decision-making with children accounted for the most common 'type' of project. This result appears to indicate that children do not see themselves as having taken the lead even in these carefully selected schools grounds projects. A simple explanation is that perhaps adults were simply in a better position to decide what developments would be necessary. Diverse rationales provide adults with legitimate roles as initiators of projects: they are the ones who are invested with the job of education of the children so they must have control over learning as problem solving; only adults can deal with the complexity of projects; children must be protected from the difficulties of adult life and project failure. Given the cultural context for children's participation in Scotland where there is a heightened sense of the need for safety in schools, it is perhaps hardly surprising that children appear to be under degrees of adult control. Yet

\section{Small Rural Schools Cumulative Respons}

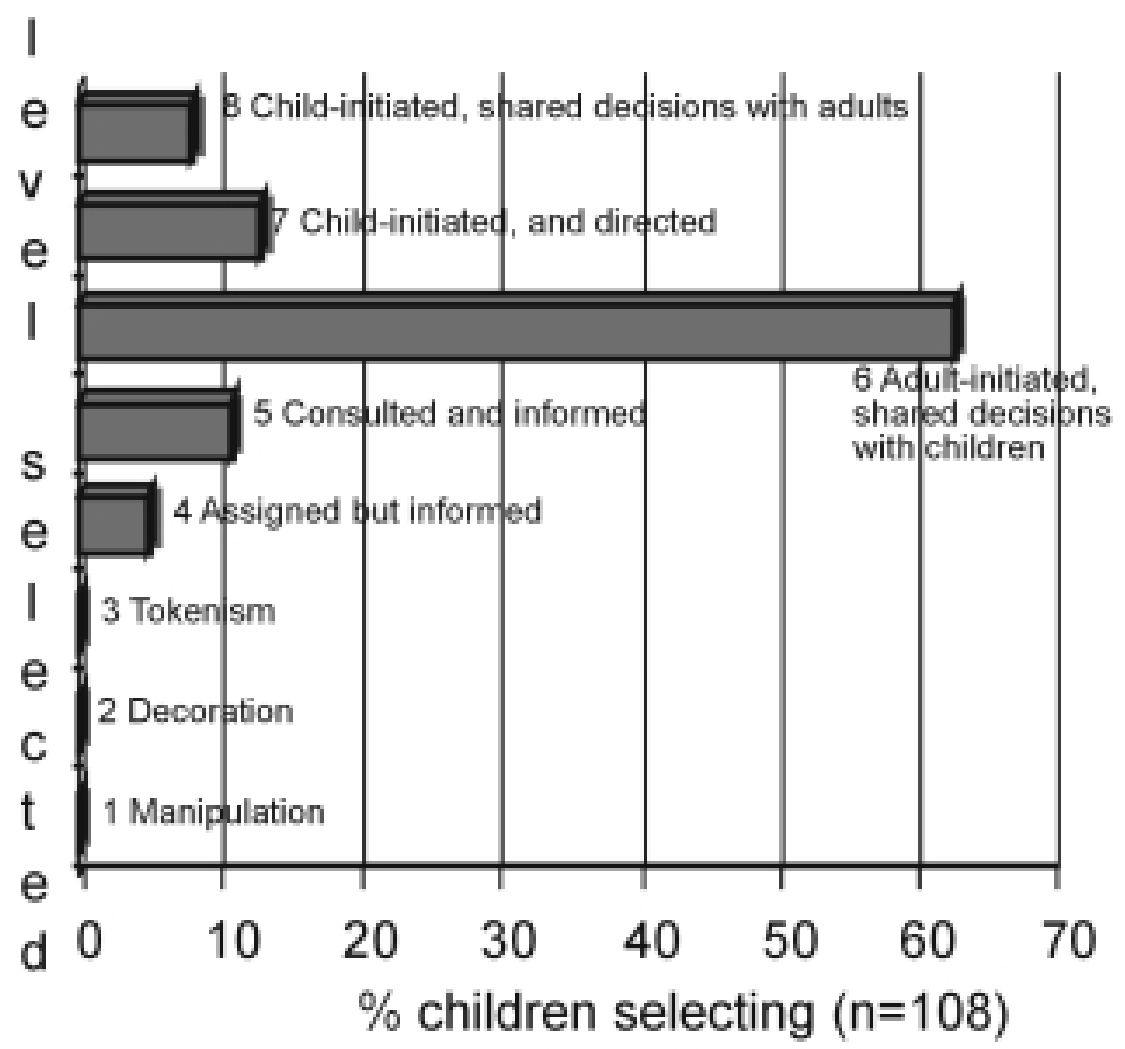

Figure 2. Levels selected for 12 projects completed in six different small rural primary schools by 108 children (ages 7-13). The relative incidence of levels was mirrored in the data from all schools. 
none of these decisions, in themselves, required children to be followers while adults took the lead. More importantly, because these were carefully chosen 'best-practice' examples, we can postulate that the level of child participation found in many 'run-of-the-mill' schools grounds projects would not reflect the same degree of child agency and shared decisionmaking with adults. Another important inference is that strong claims about 'What the children have achieved!' should be tempered with the realization that, at best, projects are largely adult initiated and, probably in the main, adult led, managed and bounded. Particular examples supported this finding. One head teacher felt that evening meetings were inappropriate to children's involvement. In another school, progress was purposefully slowed down in order to maximize children's participation in the physical work. While some school headteachers targeted participation in design aspects, others were more inclusive of children in decision-making about finance. Some involved children letter writing, making telephone calls and contributing to applications for grants while, in most schools, these tasks was left to teachers or volunteering parents.

Level 8 (child initiated, shared decisions with adults) was selected more commonly by children in small rural schools. This could be interpreted as an indicator of a more collegial atmosphere between adults and children in these institutions. Room does not allow here for any in-depth exploration of the reasons for this, but some probable factors include school size, local cultures of parent participation, social cohesiveness, and multilevel and thematic teaching practices (Mannion 1999: 170-171). Similarly, the relatively common selection of level 7 in these schools may be explained by some of the same factors and perhaps the flexibility afforded by small school size for a greater sense of pupil ownership of project work.

\section{Children's learning and engagement}

Children's engagement in projects was usually brought about through a combination of design work, work with adults (teachers and visitors), group work among the children themselves and outdoor physical work. Evidence here comes from participatory evaluations conducted in classrooms about what they regarded as having been the 'most fun', what they had 'learned the most from' and what they felt they had actually learned from projects (figure 3). Transcripts of interview evidence are used to support an analysis of findings for three of these categories.

\section{Design work}

Design work appeared to offer children opportunities for a lot of fun and their learning was also apparent from their more casual comments. Children recollected that design work involves more 'than just letting your imagination run wild' and that impediments like financial constraints affect design solutions. They seemed conscious that they were taking on an identity that was not the norm for pupils and this supports previous findings (Baldassari 
Childer's Appraisal: Which was 'Most Fun' and 'Leamed Most From' (n=93)

Total: Fun

Total: Leaming

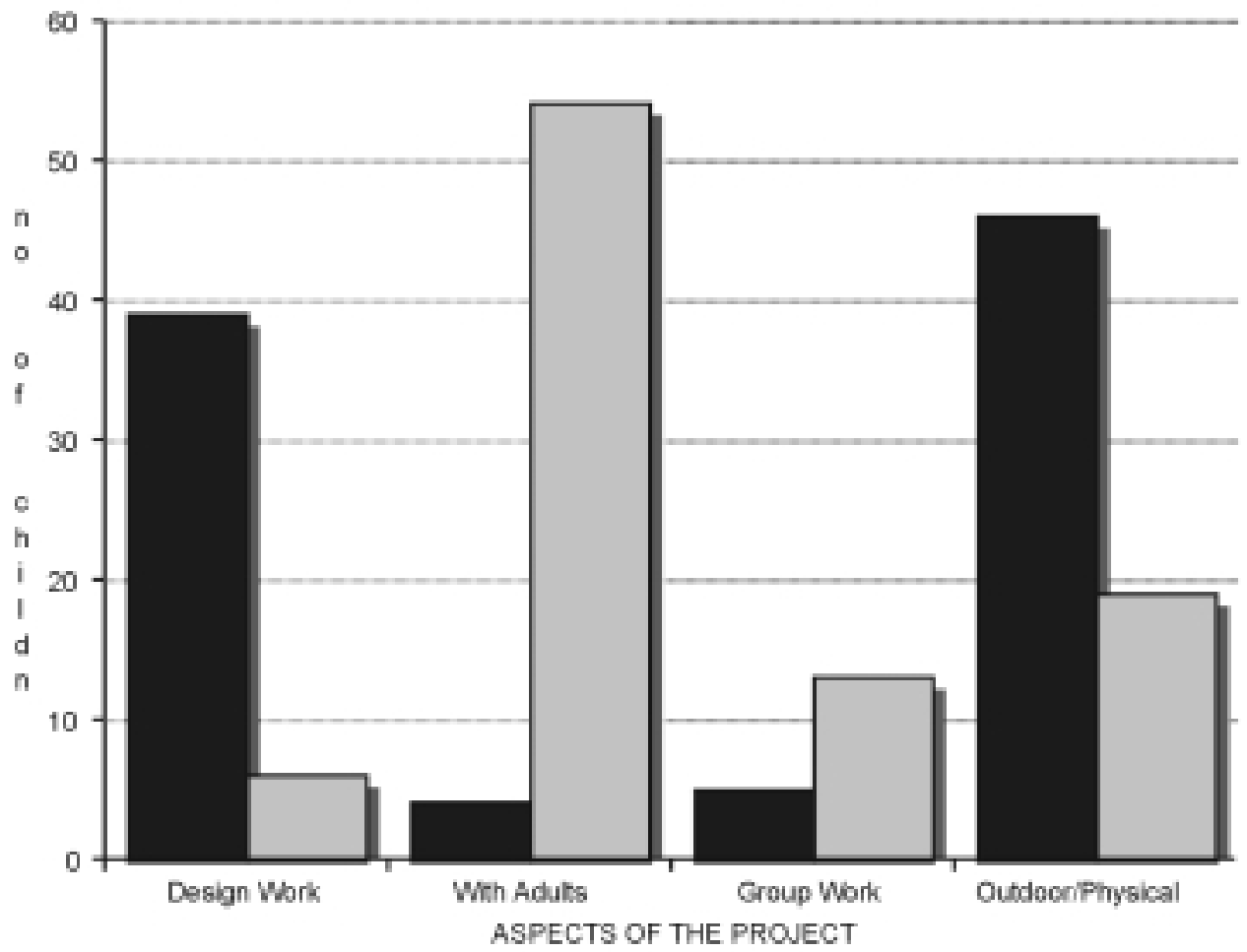

Figure 3. In five schools, 93 children (boys and girls aged 7-13) were asked to reflect on 12 school grounds development projects in which they had been involved. They assessed their involvement according to which aspects of the work were 'most fun' or from which they 'learned the most'.

et al. 1987: 262) on the impact of taking on new roles in learning. One child commented that the project 'made you feel like a professional 'cos it might happen'. Another said, 'You don't just stay in the same position, you have a new role' (Primary 4 child).

\section{Outdoor/physical work}

Children enjoyed the planning and design aspects of projects more if the projects were not seen as a 'simulations'; real changes to the environment were seen as important if participation was to be viewed positively. Children found it fun to work physically on schools grounds projects in a 'hands-on' way. The importance of providing children with opportunities for outdoor physical work that made a difference was seen as a vital component in many 
children's appraisals of their participation. 'We done too much planning and not enough doing. When they decided to do something, they brought in [volunteers] to help' (primary school child). Involvement in physically changing schools grounds was strongly connected to bringing about memorable learning. 'The project was good last year. It was good designing because we made something' (Primary 5 child, suburban primary). Some experiences indicated that children were involved in ways that were nonparticipatory because they were either manipulated, involved tokenistically or as mere decorations. If developments failed to get beyond design work without explanation, then children's comments were negative.

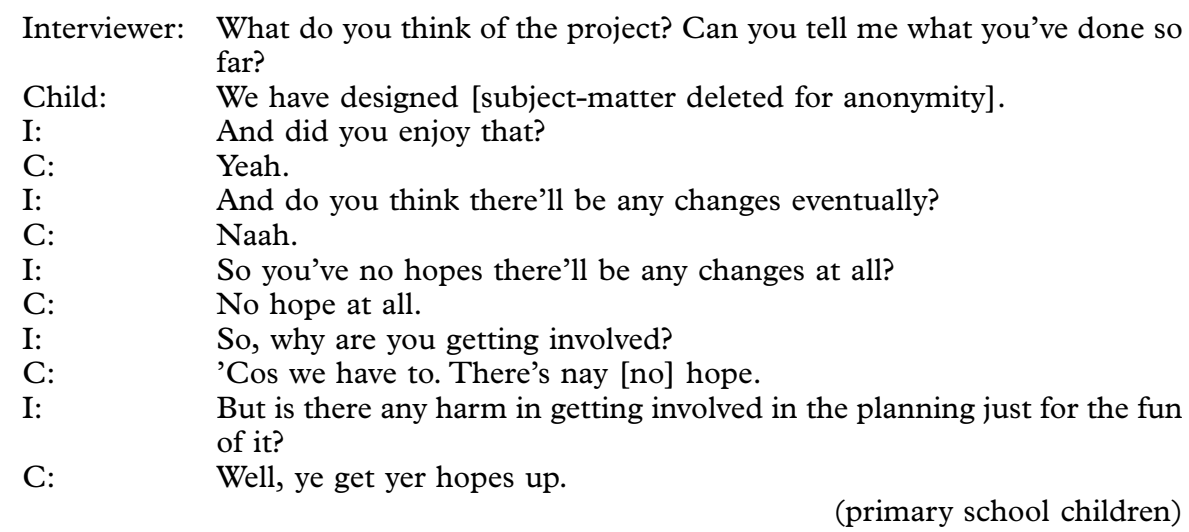

Work with adults

Teachers, and particularly visiting adults from outwith the school, made very striking contributions to children's learning. Adults involved in organizing activities for children's participation were seen as effective partners in participatory projects if they were open with children about constraints and unrealistic expectations from the projects. Children certainly learned things from adults, but their concerns were also with the manner of the adult-child interaction and the tenor of their relationships. Children respected teachers who listened to their ideas but who did not necessarily give them whatever they wanted. They looked to adults to explain clearly why things had happened the way they had. Without this form of communication, projects ran the risk of losing the trust that seemed vital for healthy participation. The adults 'weren't saying "You can't!". They told you gently [how your ideas were inappropriate or impractical]. . . . The adults didn't just snatch at you' (primary school pupils). Teacher-pupil relations appeared to shift from the norm as a result of shared engagement in action projects, especially when participation 'spilled over' into out-ofschool hours. In one case, this involved being allowed into the staff room and being able to 'swivel on the teachers' chairs'. One child commented that 'the teachers are different at the weekend'. In another school, a pupil expressed her concern about my use of Hart's ladder as a research tool, arguing that it felt more 'like a family' in her school and the distinction between 'adult' and 'child' participation did not hold for her. 


\section{Child as partner}

There are other indications that Hart's version of the ladder image may not be the most appropriate tool for making assessments about participation. Centrally, the ladder is perhaps problematic because it suggests, by its very design, that being 'higher' on the ladder is 'better' in some way, despite the caveats given by Hart himself about the variety of participatory approaches that are possible once one is above level 3 (Hart 1997: 41, figure 15). Hence, an addition to Hart's listing to allow for such a mode of participation is offered: 'Children and adults collaborate as a team'. This addition allows for participation that feels more like teamwork between adults and children, however problematic, that makes less distinction between the members in terms of age, where leadership is dispersed throughout the membership. In these collaborations members feel their involvement is less about having an individual say 'as a child' and is more about addressing change in a familial, whole-group manner. Likewise, given the problems identified with the use of the ladder metaphor, following Treseder's (1997) suggested model, a compendium of choices is given (above the line) with the figurative recognition that we must try to avoid ways of involving children that are non-participatory (below the line). The array rather than a linear ladder potentially presents practitioners with greater choice of participatory approaches than Hart's ladder (1998: 41) and may be of some use as a participatory research tool or discussion focus. The augmented typology (figure 4) supports Roche's (1999) suggestion that it is important to take on board less binary notions of citizen/non-citizen. Because adults are not the only ones bearing rights and holding some degree of citizenship, both adult and child are best viewed as 'citizens in the making'. The typology responds to the emerging need to find theoretical and methodological space for the child as partner, partial citizen (Bulmer and Rees 1996, cited in Roche 1999: 482) with adult others, or fellow citizen (deWinter 1997).

\section{Delineating and locating learning}

There is evidence from the case study that schools grounds projects brought about changes in the way children and adults related and in the way schools related to a range of other adult community members. However, the findings from the selection of 'levels of participation' indicate that adults functioned as gatekeepers on children's participation by acting as the main coordinators and managers of projects. In the main, adults were the ones to delineate what and how participation proceeded, although participation in practice took many different forms when it came to decision-making, planning and designing the physical 'work' and the administration aspects of projects. Adult decision-making and the manner of its execution supported or challenged the norms of children's social engagement within and beyond the school. Strong arguments were easily made when it came to excluding children from certain types of participation. Constraints came in the form of time and finance, fears of litigation, worries about safety, and beliefs about 


\section{The Compendium of Possible Ways of Operationalising Children's Participation}
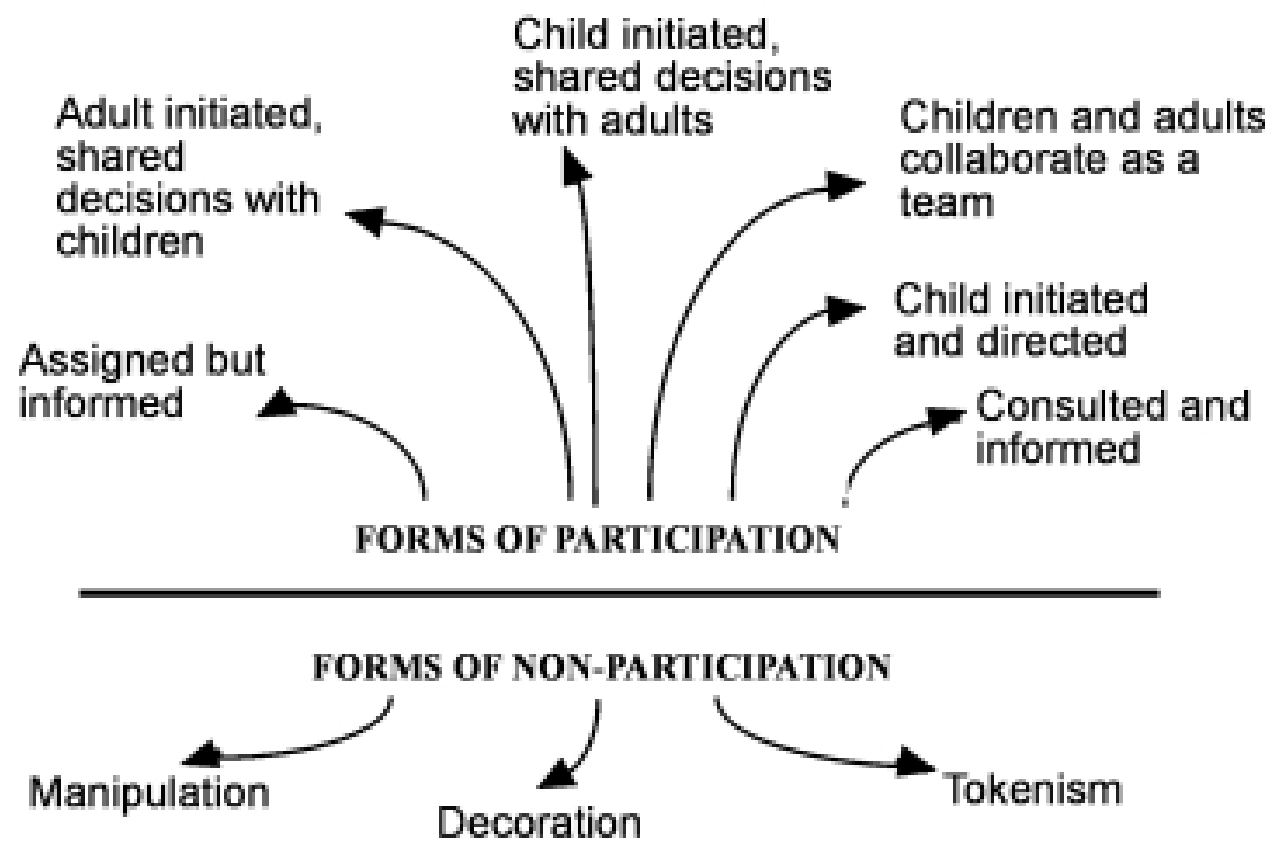

Figure 4. Compendium of modes of children's participation (see Arnstein 1979, Hart 1992, Treseder 1997 for other typologies).

children's abilities. Other arguments rest on romantic notions of childhood as a happy time free from the 'problems' of adult life. Connecting the social inclusion agenda with educational provision requires us to rethink the assumptions that underpin rationales for deferring and limiting what is on offer for children. The connections bring us to new places beyond concerns with teaching styles, diverse learner 'types', efforts to reduce school exclusions and the preparation of pupils for employment. Critically, there appeared to be a lack of 'normal' or 'routine' ways of conducting wholeschool communication and decision-making-the boundaries are unclear and shifting.

The (dis)location (Edwards and Usher 2000) of 'book' learning into school grounds development work meant a challenging of the enclosure of knowledge in texts, classrooms and formally agreed content. School grounds developments repositioned socially mediated learning between adults and children as centrally important. The shared actions of adults and children and the consequences of their work in time, space and identification were where significant learning took place. Malaguzzi (1993: 11) takes a spatial view of learning as based on relationships and located in places:

Children learn by interacting with their environment and actively transforming their relationships with the world of adults, things, events and, in original ways, their peers. In a sense, children participate in constructing their identity and the identity of others. 
Wenger (1998: 270) advocates a similar strong connectivity between identity formation, the material reality of learners and meaningful action. For Wenger, learning needs places of engagement, materials and experiences with which to build an image of the world and of themselves, and ways of having an effect on the world and making their actions matter. Three features of children's participation in schools grounds projects were intricately bound up with each other: the creation of 'new spaces', the arrival of opportunities for children's active engagement, and the shifting of the socio-cultural context for learning and the scope of what was to be learned. Education that promotes the social inclusion of children will benefit from seeing children as current (if partial) citizens and using socio-spatial opportunities for their participation. Education that seeks to advance children's social inclusion will require a shift in focus from preventing children's future social exclusion (and the attendant inward emphasis on skill acquisition while at school in order to secure employment later in life) to a new outward focus on children's contemporary engagement in society. It will reconfigure parents and children as participant-learners (in learning, education, school change) rather than as recipients or consumers of services. It will require educators to consider carefully how they delineate and/or devolve decision-making about the scope are focus of action learning projects. It will reconfigure the role of teacher from that of transmitter of pregiven knowledge to that of situated 'co-learner' with children and those who are not regular participants in school life: parents, volunteers and others. Perhaps it is not surprising that school grounds were the focus of the study. They were, perhaps, more easily populated by these 'outsiders' because they were seen as extraneous or marginal to the 'core' work of a school and hence easily encroached upon.

\section{Closings and openings}

Commentators notice that the spaces we afford children for social interaction and the policies we draw upon to connect education with the social inclusion agenda potentially limit opportunities for adult-child interaction and the enhancement of children's participation in all arenas of society. Beyond the relations between children and their parents, adultchild relations seem to be increasingly professionalized in settings designed for their care, health and education. The result is that children end up as social outsiders; things happen to the child (deWinter 1997: vii). Education that promotes the social inclusion of children would redress this balance by focussing on the relational, spatial and political aspects of learning and its boundaries. Edwards et al. (2001: 426) argued that non-exclusion was not the same as inclusion. Similarly, this paper lends support to the argument that if education is to address children's inclusion in society, it will need to be about more than trying to insure against their future exclusion from the work force. An emphasis on the child as agent will be a necessary counterbalance to a policy emphasis on the child in need.

The analysis of policy documents identified the way in which children's social inclusion via educational experience is limited in scope, deferred until 
some 'adult time' and obscured through an emphasis on children's deficits. In school grounds developments, there was evidence that these limitations and deferrals were being challenged. However, we should bear in mind that despite welcome levels of child participation, it was the adults who played the central role in delineating and managing this. Recent shifts in policy talk have been identified that see children as active citizens in their own right. This requires a reconsideration of both child and adult identifications. By inference, the impacts of education for the social inclusion of children will likely be felt by everyone including adults and perhaps especially by those who are not commonly found in and around schools. In these new partnerships, the teachers and managers of schools will also be required to do some learning and participating. A recognition of the ambiguity and contestation of children's voices and participation rights (Lee 1999) means that adult roles will be rendered ambiguous too.

This paper proposes that educational experience for the social inclusion of children characteristically will be relational, political and spatial in its source, substance and purpose (also Mannion and I'Anson 2002). Quite profound educational opportunities were mobilized within, and because of, involvement in these adult-child socio-spatial identity projects. The creation of new spaces, the arrival of opportunities for new forms of identification and the altering of the form and scope of learning appeared to co-specify in complex rather than in linearly ways. What made these projects distinctive was their need to engage children and adults in the construction of places and knowledge where the outcomes were not easily predetermined. Theoretically, the argument is that the creation of new 'space', the arrival of opportunities for new forms of identification for partial (adult and child) citizens, and the uncertainty of the form and scope of what will be learned appear to be co-specific and characteristic of socially inclusive learning. Popkewitz (2001: 202) reminds us that if the citizen is to be an actor and agent of change, change cannot be predicted because participation needs to be negotiated in an uncertain world. Practically, the challenge is to devise curricula as itineraries of transformative experiences of participation (Wenger 1998: 272) within and about sites that are socially central for adults and children rather than a list of subject-matters. A curriculum for the social inclusion of children may need to be 'suspended in the space between . . . where dissimilar ideas might meet, mingle and mutate' (Dahlberg et al. 1999: 171-172), but it is doubtful whether curricular reforms can easily reflect this necessary ingredient of uncertainty. In practice, this means we need to be careful about the drive to find definitive 'design solutions' whatever the project. Curricular spaces need to be continually remade anew. Redesigned space, by enclosing new people, ideas and things, will also exclude others. Redesigning space offers the possibility of new openings and new learning.

Shifts in policy towards active citizenship and community engagement, however welcome, may not necessarily connect with mainstream 'indoor' school practice. Schools seeking to generate learning that addresses the social inclusion of children will need to remember that these experiences are likely to be relational, political and spatial in their source, substance and purpose and the consequences will not just be for children. The rise in 
interest in the ways in which identity, space and place interconnect means that the educational spaces of the school cannot be isolated any longer from the home, the street and the workplace (Edwards and Usher 2000: 72). Despite the potential for new forms of exclusion, education that promotes children's social inclusion will need to find pedagogic space for adults and children as active (if partial) citizens. These pedagogic spaces would offer opportunities for new forms of adult-child learning relations, the construction of new learning environments and intergenerational experiments with ways of being in a place.

\section{References}

Aries, P. (1973) Centuries of Childhood/L'enfant et la vie familiale sous l'ancien regime (Harmondsworth: Penguin).

Arnstein, S. R. (1979) Eight rungs on the Ladder of Citizen Participation. Fournal of the American Institute of Planners.

Baldassari, C., Lehman, S. and Wolfe, M. (1987) Imagining and creating alternative environments with children. In C. S. Weinstein and T. G. David (eds), Spaces for Children (London: Plenum).

Beattie Committee (1999) Implementing Inclusiveness: Realising Potential (Edinburgh: Scottish Executive Stationery Office).

Bernstein, B. (1970) Education cannot compensate for society. New Society, 387, 344-347.

Bulmer, M. and Rees, A. M. (eds) (1996) Citizenship Today: The Contemporary Relevance of T. H. Marshall (London: University College London Press).

Byrne, D. (1999) Social Exclusion (Buckingham: Open University Press).

Carrington, S. (1999) Inclusion needs a different school culture. International fournal of Inclusive Education, 3, 257-268.

Corbett, J. (1999) Inclusive education and school culture. International fournal of Inclusive Education, 3, 53-61.

Cunningham, H. (1995) Children and Childhood in Western Society Since 1500 (New York: Longman).

Dahlberg, G., Moss, P. and Pence, A. (1999) Beyond Quality in Early Childhood Education (London: Falmer).

DeWinter, M. (1997) Children as Fellow Citizens: Participation and Commitment (Oxford: Radcliffe Medical).

Dorrian, L., Tisdall, K. and Hamilton, D. (1999) Taking the Initiative-Promoting Young People's Participation in Public Decision Making in Scotland (London: Carnegie UK Trust and Children in Scotland, Carnegie Young People Initiative).

Education, Culture and Sport Committee (2002) Discussion Paper: Inquiry into the Purposes of Education (Edinburgh: HMSO).

Edwards, R., Armstrong, P. and Miller, N. (2001) Include me out: critical readings of social exclusion, social inclusion and lifelong learning. International fournal of Lifelong Education, 20, 417-428.

Edwards, R. and Usher, R. (2000) Globalisation and Pedagogy: Space, Place and Identity (London: Routledge).

Field, J. (2000) Lifelong Learning and the New Educational Order (London: Trentham).

Freeman, M. (2000) The future of children's rights. Children and Society, 14, 277-293.

Hart, R. (1987) Children's participation in planning and design. In C. S. Weinstein and T. G. David (eds), Spaces for Children (London: Plenum).

Hart, R. (1992) Children's participation: from tokenism to citizenship (Florence: International Child Development Centre/UNICEF).

Hart, R. (1997) Children's Participation: The Theory and Practice of Involving Young Citizens in Community Development and Environmental Care (London: Earthscan).

Hayton, A. (ed.) (1999) Tackling Disaffection and Social Exclusion: Education Perspectives and Policies (London: Kogan Page).

Holden, C. and Clough, N. (1998) Children as Citizens: Education for Participation (London: Jessica Kingsley).

Lankshear, C., Peters, M. and Knobel, M. (1996) Critical pedagogy and cyberspace. In H. A. Giroux, C. Lankshear, P. McLaren and M. Peters (eds), Counternarratives (London: Routledge). 
Learning and Teaching Scotland (2000) Education for Citizenship: A Paper for Discussion and Consultation (Edinburgh: Scottish Executive Stationery Office).

Learning and Teaching Scotland (2002) Education for Citizenship in Scotland: A Paper for Discussion and Development (Edinburgh: Scottish Executive Stationery Office) [http://www.LTScotland.com/ citizenship/paper] (accessed 22 July 2002).

Lee, N. (1999) The challenge of childhood, distributions of childhood's ambiguity in adult institutions. Childhood, 6, 455-474.

Malaguzzi, L. (1993) For an education based on relationships. Young Children, 11, 9-13.

Mannion, G. (1999) Children's Participation in Changing School Grounds and Public Play Parks in Scotland. Unpublished doctoral thesis, University of Stirling.

Mannion, G. and I'Anson, J. (2002) Beyond the Disneyesque: does children's participation alter the state of adults' learning? Paper presented at SCUTREA (Standing Conference on University Teaching and Research in the Education of Adults), July, 2002: The Altered States of Adult Learning (Stirling: University of Stirling)

Matthews, H., Limb, M. and Taylor, M. (1999) Young people's participation and representation in society. Geoforum, 30, 135-144.

Nixon, J., Allan, J. and Mannion, G. (2001) Educational renewal as democratic practice: 'new' community schooling in Scotland. International fournal of Inclusive Education, 5, 329-352.

O'Kane, C. (2000) The development of participatory techniques: facilitating children's views about decisions which affect them. In P. Christensen and A. James (eds), Research With Children (London: Falmer).

Parsons, C., Benns, L., Hailes, J. and Howlett, K. (1994) Excluding Primary School Children (Kent: Christ Church College).

Popkewitz, T. S. (2001) Rethinking the political: reconstituting national imaginaries and producing difference. International Fournal of Inclusive Education, 5, 179-207.

Roberts, M. (2001) Childcare policy. In P. Foley, J. Roche and S. Tucker (eds), Children in Society: Contemporary Theory, Policy and Practice (Hampshire: Palgrave)

Roche, J. (1999) Children: rights, participation and citizenship. Childhood, 6, 475-493.

Sammons, P., Power, S., Robertson, P., Elliot, K., Campbell, C. and Whitty, G. (2002) National Evaluation of the New Community Schools Pilot Programme in Scotland, Phase 1 1999-2002. Interchange, 76 (Edinburgh: Scottish Executive Stationery Office).

Scottish Executive (2002) Scottish Executive Response to the Report from the Education Culture and Sport Committee on the Inquiry into the Need for a Children's Commissioner in Scotland (Edinburgh: Scottish Executive Stationery Office).

Scottish Office (1998) New Community Schools Prospectus (Edinburgh: Scottish Office).

Scottish Office (1999) Social Inclusion-Opening the Door to a Better Scotland (Edinburgh: Scottish Executive Stationery Office) [http://www.scotland.gov.uk/library/documents-w7/sima-03.htm] (accessed July 2002).

Stake, R. E. (1995) The Art of Case Study Research (Thousand Oaks: Sage).

The Qualifications and Curriculum Authority (2000) Citizenship at Key Stages 3 and 4: Initial Guidance for Schools (Suffolk: QCA Publications).

Treseder, P. (1997) Empowering Children and Young People: Training Manual (London: Children's Rights Office and Save the Children).

UNICEF (1995) The United Nations Convention on the Rights of the Child (London: UNICEF).

Wenger, E. (1998) Communities of Practice: Learning, Meaning and Identity (Cambridge: Cambridge University Press). 


\section{Annotations from TIED 100180.pdf}

\section{Page 1}

Annotation 1; Label: Author Query; Date: 6/3/2003 5:32:36 pm

AQ1 - Page 1

Social Exclusion Unit 2001 - Not cited in refs.

\section{Page 3}

Annotation 1; Label: Author Query; Date: 6/3/2003 5:33:26 pm

AQ1 - Page 3

Social Exclusion Unit 2001 - Not cited in refs.

\section{Page 4}

Annotation 1; Label: Author Query; Date: 6/3/2003 5:34:25 pm

AQ2 - Page 4

Please check sense of text - "The consistent emphasis ... children and families."

\section{Page 13}

Annotation 1; Label: Author Query; Date: 6/3/2003 5:35:50 pm

AQ3 - Page 13

"Hence, an addition ... is offered:" - OK?

\section{Page 15}

Annotation 1; Label: Author Query; Date: 6/3/2003 5:37:05 pm

AQ4 - Page 15

"It will required educators ... learing projects." - OK?

\section{Page 17}

Annotation 1; Label: Author Query; Date: 6/3/2003 5:38:22 pm

AQ5 - Page 17

Arnstein - Vol \& Page numbers?

\section{Page 18}

Annotation 1; Label: Author Query; Date: 6/3/2003 5:39:17 pm

AQ6 - Page 18

Parsons - Town of publication?

Annotation 2; Label: Author Query; Date: 6/3/2003 5:39:55 pm

AQ7 - Page 18

Roberts - Town of publication?

Annotation 3; Label: Author Query; Date: 6/3/2003 5:40:31 pm

AQ8 - Page 18

The Qualifications and Curriculum Authority - Town of publication? 


\title{
AN AGREEMENT FOR THE TRANSFER OF COPYRIGHT
}

\author{
IN RELATION TO THE CONTRIBUTION OF YOUR ARTICLE ('THE ARTICLE') ENTITLED:
}

BY:

WHICH WILL BE PUBLISHED IN T-IED

In order to ensure both the widest dissemination and protection of material published in our Journal, we ask authors to assign the rights of copyright in the articles they contribute. This enables Taylor \& Francis Ltd ('us' or 'we') to ensure protection against infringement. In consideration of the publication of your Article, you agree to the following:

1. You assign to us with full title guarantee all rights of copyright and related rights in your Article. So that there is no doubt, this assignment includes the assignment of the right to publish the Article in all forms, including electronic and digital forms, for the full legal term of the copyright and any extension or renewals. Electronic form shall include, but not be limited to, microfiche, CD-ROM and in a form accessible via on-line electronic networks. We shall in turn grant you the right to use the ideas (but not the actual content) contained within the Article in future works, including lectures, press releases and reviews, provided that you acknowledge its prior publication in the Journal.

2. We shall prepare and publish your Article in the Journal. We reserve the right to make such editorial changes as may be necessary to make the Article suitable for publication, or as we reasonably consider necessary to avoid infringing third party rights or law; and we reserve the right not to proceed with publication for whatever reason.

3. You hereby assert your moral rights to be identified as the author of the Article according to the UK Copyright Designs \& Patents Act 1988.

4. You warrant that you have at your expense secured the necessary written permission from the appropriate copyright owner or authorities for the reproduction in the Article and the Journal of any text, illustration, or other material. You warrant that, apart from any such third party copyright material included in the Article, the Article is your original work, and does not infringe the intellectual property rights of any other person or entity and cannot be construed as plagiarising any other published work. You further warrant that the Article has not been previously assigned or licensed by you to any third party and you will undertake that it will not be published elsewhere without our written consent.

5. In addition you warrant that the Article contains no statement that is abusive, defamatory, libelous, obscene, fraudulent, nor in any way infringes the rights of others, nor is in any other way unlawful or in violation of applicable laws.

6. You warrant that wherever possible and appropriate, any patient, client or participant in any research or clinical experiment or study who is mentioned in the Article has given consent to the inclusion of material pertaining to themselves, and that they acknowledge that they cannot be identified via the Article and that you will not identify them in any way.

7. You warrant that you shall include in the text of the Article appropriate warnings concerning any particular hazards that may be involved in carrying out experiments or procedures described in the Article or involved in instructions, materials, or formulae in the Article, and shall mention explicitly relevant safety precautions, and give, if an accepted code of practice is relevant, a reference to the relevant standard or code. 
8. You shall keep us and our affiliates indemnified in full against all loss, damages, injury, costs and expenses (including legal and other professional fees and expenses) awarded against or incurred or paid by us as a result of your breach of the warranties given in this agreement.

9. You undertake that you will include in the text of the Article an appropriate statement should you have a financial interest or benefit arising from the direct applications of your research.

10. If the Article was prepared jointly with other authors, you warrant that you have been authorised by all co-authors to sign this Agreement on their behalf, and to agree on their behalf the order of names in the publication of the Article. You shall notify us in writing of the names of any such co-owners.

11. This agreement (and any dispute, proceeding, claim or controversy in relation to it) is subject to English law and the jurisdiction of the Courts of England and Wales. It may only be amended by a document signed by both of us.

Signed

Print name

Date 